\title{
Detecting seismic IR anomalies in bi-angular Advanced Along-Track Scanning Radiometer data
}

\author{
P. Xiong ${ }^{1,2}$, X. F. Gu ${ }^{1}$, Y. X. Bi ${ }^{3}$, X. H. Shen ${ }^{2}$, Q. Y. Meng ${ }^{1}$, L. M. Zhao ${ }^{1}$, C. L. Kang ${ }^{4}$, L. Z. Chen ${ }^{2}$, F. Jing ${ }^{2}$, N. Yao ${ }^{5}$, \\ Y. H. Zhao ${ }^{5}$ X. M. Li ${ }^{5}$, Y. Li ${ }^{5}$, and J. T. Dong ${ }^{5}$ \\ ${ }^{1}$ State Key Laboratory of Remote Sensing Science, Institute of Remote Sensing and Digital Earth, \\ Chinese Academy of Sciences, Beijing, China \\ ${ }^{2}$ Institute of Earthquake Science, China Earthquake Administration, Beijing, China \\ ${ }^{3}$ School of Computing and Mathematics, University of Ulster, UK \\ ${ }^{4}$ China Earthquake Networks Center, China Earthquake Administration, Beijing, China \\ ${ }^{5}$ Beijing Institute of Space Mechanics and Electricity, Beijing, China
}

Correspondence to: X. F. Gu (xfgu@irsa.ac.cn)

Received: 23 August 2012 - Published in Nat. Hazards Earth Syst. Sci. Discuss.: Revised: 2 July 2013 - Accepted: 3 July 2013 - Published: 20 August 2013

\begin{abstract}
This paper presents a validation and confutation analysis using the methods of the robust satellite data analysis technique (RST) to detect seismic anomalies within the bi-angular Advanced Along-Track Scanning Radiometer (AATSR) data based on spatial/temporal continuity analysis. The distinguishing feature of our method is that we carried out a comparative analysis of seismic anomalies from bi-directional observation, which could help understanding seismic thermal infrared (TIR) anomalies. The proposed method has been applied to analyse bi-angular AATSR gridded brightness temperature data with longitude from 5 to $25^{\circ} \mathrm{E}$ and latitude from 35 to $50^{\circ} \mathrm{N}$ associated with the earthquake that occurred in Abruzzo, Italy, on 6 April 2009, and a full data set of $7 \mathrm{yr}$ data from 2003 to 2009 during the months of March and April has been analysed for validation purposes. Unperturbed periods (March-April 2008) have been considered for confutation analysis. Combining with the tectonic explanation of spatial and temporal continuity of the abnormal phenomena, along with the analysed results, a number of anomalies could be associated with possible seismic activities, which follow the same time and space. Therefore, we conclude that the anomalies observed from 29 March 2009 to 5 April 2009, about eight days before the Abruzzo earthquake, could be earthquake anomalies.
\end{abstract}

\section{Introduction}

By studying remote sensing satellite data, researchers have found various abnormal events in the lithosphere, atmosphere and ionosphere prior to large earthquakes, which are reflected in thermal infrared (TIR) anomalies (Gorny et al., 1988; Tronin, 1996; Tramutoli et al., 2005; Pulinets et al., 2006), and ionospheric anomalies (Pulinets and Boyarchuk, 2004; Hayakawa, 2000; Liu et al., 2004; Sarkar et al., 2007; Parrot et al., 2006) prior to the earthquake events. The latest advancements in lithospheric-atmospheric-ionospheric models provide a possible explanation for the origin of these phenomena (Pulinets and Boyarchuk, 2004; Pulinets and Ouzounov, 2011; Liperovsky et al., 2005, 2008, 2011; Umarkhodgaev et al., 2012), permitting us to explore possible new studies of the spatial and temporal variability of remote sensing data before and during major earthquakes.

Several studies have recently been carried out to analyse thermal infrared anomalies appearing in the area of earthquake occurrence a few days before the seismic shock. These studies analytically compare images of pre- (vs. post-) earthquake satellite TIR imagery (Tronin et al., 2002), study outgoing longwave radiation (OLR) data and identify anomalous variations prior to a number of medium to large earthquakes (Defu et al., 1997; Ouzounov et al., 2007; Xiong et al., 2010), perform a multispectral thermal infrared component analysis during earthquakes by using land surface 
temperature (LST) (Ouzounov and Freund, 2004; Tronin et al., 2004), and assess the anomalous surface latent heat flux (SLHF) peaks a few days prior to the main earthquake event (Dey and Singh, 2003; Cervone et al., 2004; Qin et al., 2011).

The main problems associated with these studies are lack of rigorous definition for TIR anomalies and the absence of a convincing testing step based on a validation/confutation approach. A possible solution to these problems is to employ a new approach and an advanced data analysis technique to detect earthquake anomalies embedded in TIR remote sensing satellite data. Recently, a data analysis technique named the robust satellite data analysis technique (RST) (Tramutoli, 2007) has been proposed for natural and environmental hazards monitoring and mitigation. This technique has already been validated in the case of many earthquakes (Tramutoli et al., 2001, 2005; Filizzola et al., 2004; Corrado et al., 2005; Aliano et al., 2007, 2008; Genzano et al., 2007, 2009, 2010; Pergola et al., 2010).

During the seismic activities, local change of infrared information along the active faults is small, but it shows clear anisotropy. The Advanced Along-Track Scanning Radiometer (AATSR) onboard ESA's Envisat spacecraft has a viewing geometry where each terrestrial scene is viewed at two angles, at nadir and at a forward angle of $55^{\circ}$ (Llewellyn-Jones et al., 2001), these dual views can be used to detect seismic anomalies from bi-directional observation based on infrared anisotropy of seismic activities.

In this paper we propose to use a RST approach as a data analysis tool to detect seismic anomalies within bi-angular AATSR data. We have undertaken a validation and confutation approach in order to determine whether causes (e.g. meteorological) that are different from seismic activity could be responsible for the TIR anomalies. A comparative analysis of seismic anomalies reflected in bi-directional observation provides us with a further understanding of seismic TIR anomalies.

The proposed RST approach has been applied to analyse the AATSR gridded brightness temperature data associated with the Abruzzo, Italy, earthquake that occurred on 6 April 2009 (Fig. 1). Combined with the tectonic explanation of the spatial and temporal continuity of the abnormal phenomena, the analysed results have indicated a number of anomalies associated with the possible seismic characteristics of the Abruzzo earthquake.

\section{The bi-angular AATSR data}

The AATSR onboard ESA's Envisat spacecraft has three visible/near-infrared channels at $0.55,0.67$ and $0.87 \mu \mathrm{m}$, designed specifically for remote-sensing applications over land and a visible channel at $1.6 \mu \mathrm{m}$ which is used primarily for cloud clearing, as well as three channels at the thermal infrared wavelengths of 3.7, 11 and $12 \mu \mathrm{m}$, from which surface temperatures are derived over both sea and land

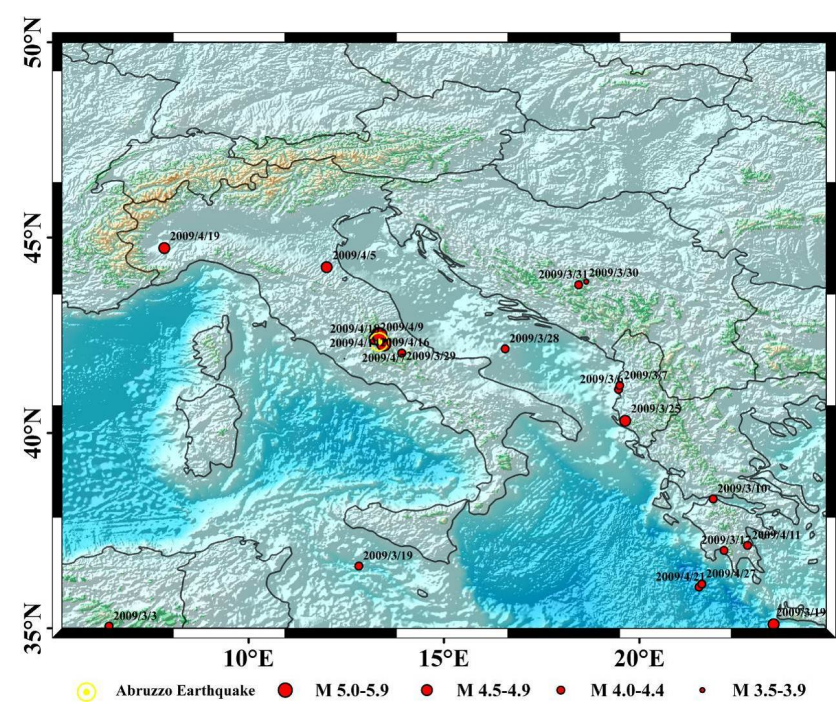

Fig. 1. Historic seismicity (from March 2009 to April 2009) of the Abruzzo region. The epicentre of the Abruzzo earthquake that occurred on 6 April 2009 is marked with a yellow bullseye.

surfaces (Llewellyn-Jones et al., 2001). The nominal spatial resolution of AATSR is $1 \mathrm{~km} \times 1 \mathrm{~km}$ in the nadir view and $1.5 \mathrm{~km} \times 2 \mathrm{~km}$ in the forward view, with a swath width of about $500 \mathrm{~km}$. Equator crossing time is 10:00 local time (descending node) and revisit time is about 3 days (Coll et al., 2012).

The AATSR has two on-board calibration mechanisms, low-noise detectors and mechanical coolers that provide high radiometric accuracy and stability to the TIR data (better than $0.05 \mathrm{~K}$ for the 11 and $12 \mu \mathrm{m}$ bands). A special feature of the AATSR is its conical scanning mechanism to give a dual view of the Earth's surface, first in the forward view at an angle of around $55^{\circ}$, and $150 \mathrm{~s}$ later in the nadir view at an angle close to vertical (from 0 to $21.7^{\circ}$ ). From two views with different atmospheric path lengths, it is possible to obtain independent information about the atmospheric contributions to the signal, and perform an accurate atmospheric correction and thus enable more precise data (ESA, 2007; Llewellyn-Jones et al., 2001).

The AATSR data used in this paper are usually provided in so called Gridded Brightness Temperature/Reflectance (GBTR) product, which is the single Level 1B product from AATSR. It contains cloud-free top-of-atmosphere (TOA) brightness temperature (BT) values for the three infrared channels and reflectance values for the $1.6 \mu \mathrm{m}$ and visible channels, and all pixels are co-located and resampled to a $1 \mathrm{~km}$ latitude-longitude grid (ESA, 2007). In this paper we propose to utilise the bi-angular $12 \mu \mathrm{m}$ brightness temperature data to detect seismic anomalies using the robust satellite technique. 


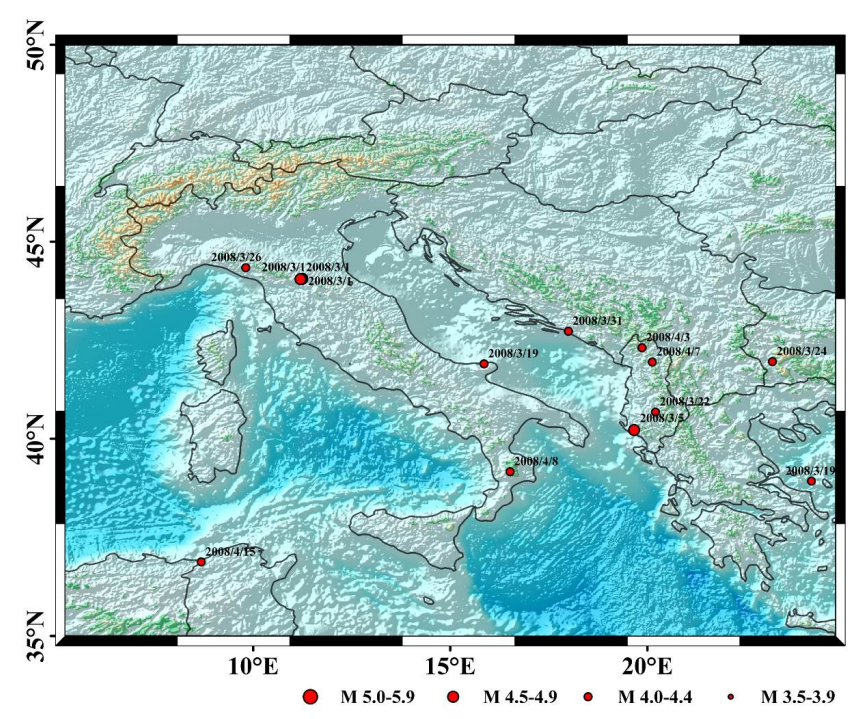

Fig. 2. Historic seismicity (March 2008 to April 2008) of the Abruzzo region.

\section{Abruzzo earthquake}

In this study, the Abruzzo earthquake with magnitude $M=$ 6.3 is selected for evaluating the proposed methods. It occurred on the 6 April 2009 at 01:32:39 GMT, the location of the epicentre is at $42.33^{\circ} \mathrm{N}, 13.33^{\circ} \mathrm{E}$ in the L'Aquila area of central Italy (Fig. 1), at a depth of $8.8 \mathrm{~km}$ (5.5 miles). At least 287 people were killed, 1000 injured, 40000 made homeless and 10000 buildings were damaged or destroyed. The main earthquake was followed by a series of smaller aftershocks (USGS, 2009).

The tectonic summary of this earthquake is described as follows: it occurred as a result of normal faulting on a NWSE oriented structure in the central Apennines, a mountain belt that runs from the Gulf of Taranto in southern Italy to the southern edge of the Po Basin in northern Italy. Geologically, the Apennines are largely an accretionary wedge formed as a consequence of subduction. This region is tectonically and geologically complex, involving both subduction of the Adria Microplate beneath the Apennines from east to west, continental collision between the Eurasian and African plates building the Alpine mountain belt further to the north and the opening of the Tyrrhenian Basin to the west. The evolution of this system has caused the expression of all different tectonic styles acting at the same time in a broad region surrounding Italy and the central Mediterranean. The earthquake on 6 April 2009 is related to normal faulting and the east-west extensional tectonics that dominate along the entire Apennine belt, primarily a response to the Tyrrhenian Basin opening faster than the compression between the Eurasian and African plates (USGS, 2009).

\section{Methodology}

There are several methods to choose for the analysis of TIR data, mainly including the eddy field calculation mean (Defu et al., 1997; Ouzounov et al., 2007), the wavelet timefrequency analysis (Cervone et al., 2004; Xiong et al., 2009) and the RST (Tramutoli, 1998, 2007). The RST method is based on a preliminary multi-temporal analysis on several years of satellite TIR records, which is devoted to characterize the TIR signal for each pixel of the satellite image processed. This previous study concluded that, anomalous TIR could be identified within TIR data related to an earthquake (Tramutoli et al., 2001, 2005, 2007; Filizzola et al., 2004; Aliano et al., 2007, 2008; Genzano et al., 2009, 2010; Pergola et al., 2010). Each step of the RST method for detecting seismic anomalies using bi-angular Advanced Along-Track Scanning Radiometer data will be explained and detailed in the following.

\subsection{Calculating the differential variable $\Delta T$}

Calculating differential variable $\Delta T$ is expected to reduce possible contributions due to day-to-day and/or year-to-year climatological changes and/or season time-drifts. The differential variable $\Delta T$ is the value of the difference between the punctual value of AATSR brightness temperature and its spatial average computed on the investigated area by taking consideration of only cloud-free locations, all belonging to the same underlying surface, land or sea.

The first step in calculating the differential variable $\Delta T$ is to build a cloud mask: hereinafter, we use the nadir-forward tests (Závody et al., 2000), which are based on the idea that for clear pixels there should be correlation between the difference in bi-angular AATSR brightness temperature between the nadir and forward view measurements at 11 and $12 \mu \mathrm{m}$ brightness temperatures, since both depend on the atmospheric characteristics, principally the water vapour loading. This relationship has been determined using radiative transfer modelling applied to an ensemble of atmospheric profiles. For each pixel the difference $T 11-T 12$ is determined, and used to predict the view difference using this relationship. The actual view difference is compared with the prediction, and if they differ by more than a pre-defined threshold, the pixel is assumed to be cloudy (ESA, 2007), and after performing the cloud detection one can build an image $\mathrm{CM}(x, y)$ for each pixel $x, y$ of the scene $\mathrm{CM}=1$ or $\mathrm{CM}=0$ if the location has been recognized as clear or cloudy, respectively. 

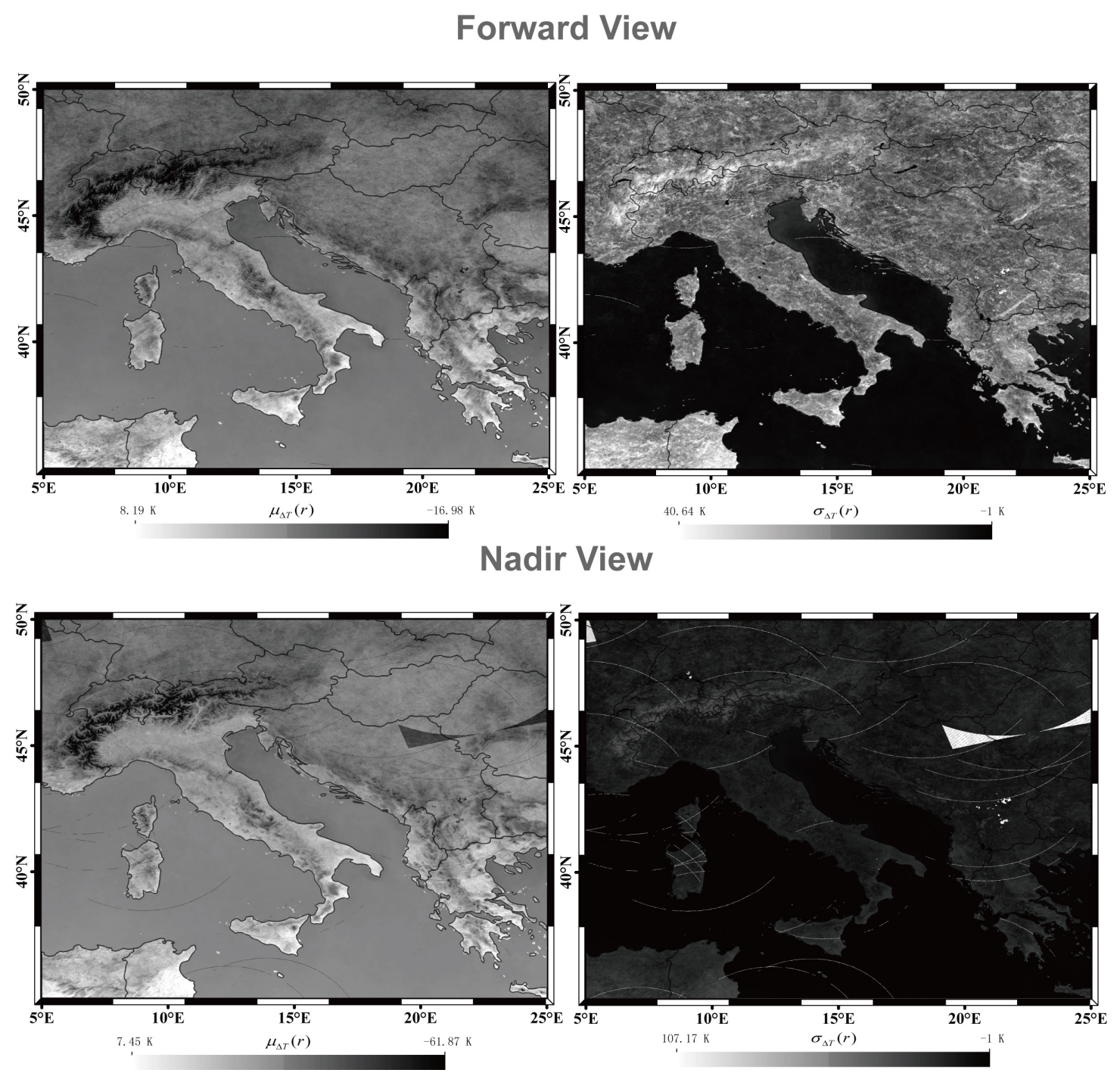

Fig. 3. The mean (left panels) and the standard deviation (right panels) of the reference fields for the investigated area of forward view and nadir view computed from bi-angular AATSR data from 2003 to 2009 during the months of March.

Given the image pixel latitude and longitude, the surface type for each image pixel is derived from land/sea mask information obtained by an external AATSR auxiliary product; after performing the land/sea identification one can build an image $\operatorname{LS}(x, y)$ having for each pixel $x, y$ of the scene with $\mathrm{LS}=1$ or $\mathrm{LS}=0$ if the location has been recognized as sea or land.

Computing the average $T(t)$ for the sea using only pixels over the scene which have $\mathrm{CM}=1$ and $\mathrm{LS}=1$ and for the land using only pixels over the scene which have $\mathrm{CM}=1$ and $\mathrm{LS}=0$, the last step is to calculate the differential variable $\Delta T$ by using the formula

$\Delta T=T(r, t)-T(t)$, where $r \equiv(x, y)$ represents location coordinates of the pixel centre on a satellite image, and $t$ is the time of image acquisition.

\subsection{Calculating the reference field}

In order to calculate the reference field for this study, we use a binning algorithm to preprocess the selected data, in which binning refers to the process of distributing the contributions of pixels to be processed in satellite coordinates to a fixed grid using a geographic reference system. In most cases a sinusoidal projection is used to generate a grid comprising a fixed number of equal area bins with global coverage (Campbell et al., 1995).

We use cloud free records from the selected data set $(t \in$ $\tau)$ to compute the reference fields for mean $\mu_{\Delta T}(r)$ and 

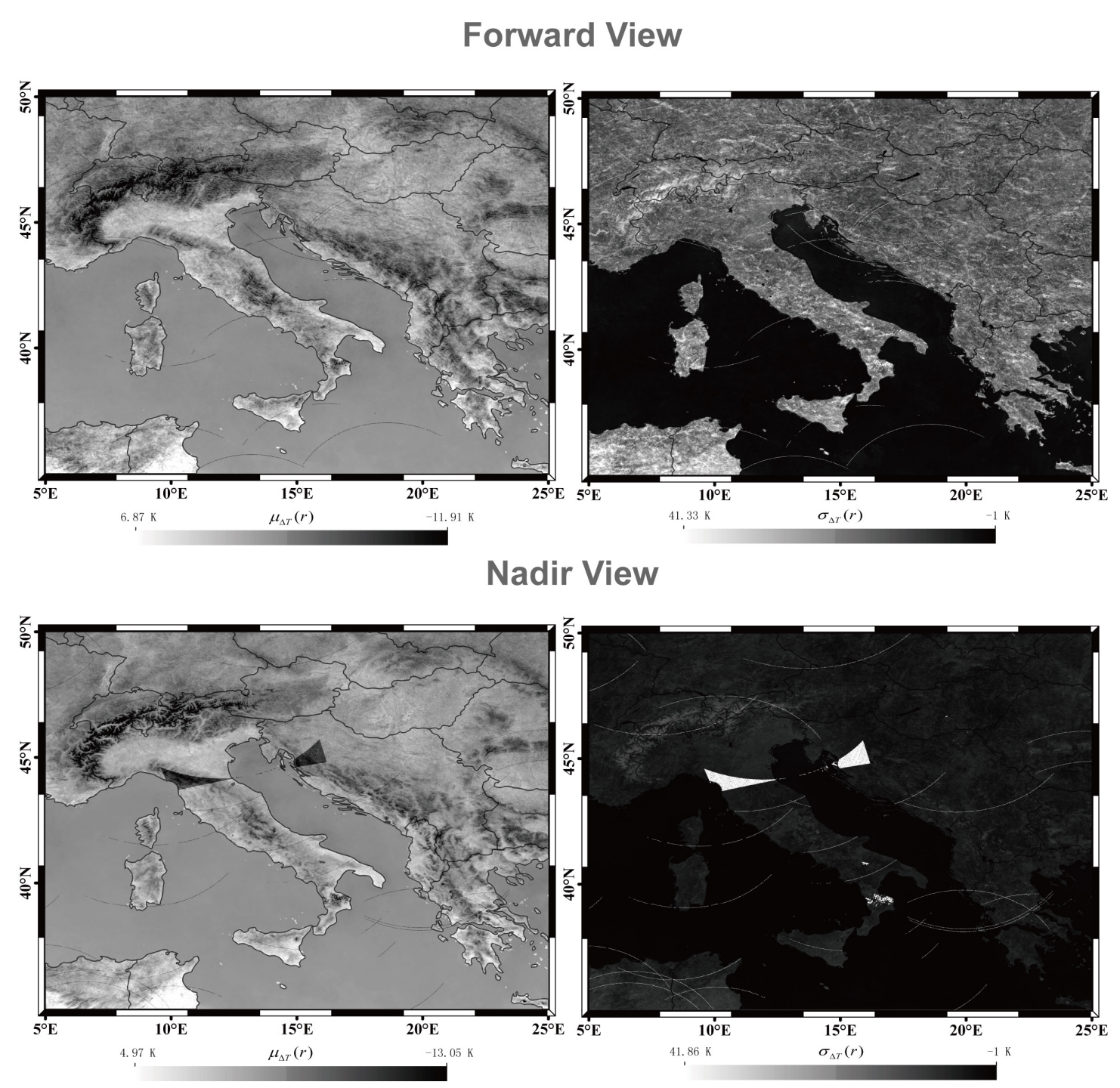

Fig. 4. Reference fields for the investigated area of forward view and nadir view computed from bi-angular AATSR data from 2003 to 2009 during the months of April.

standard deviation $\sigma_{\Delta T}(r)$ at the location $r \equiv(x, y)$ using the following equations:

$\mu_{\Delta T}(r)=\frac{1}{N} \sum_{t \in \tau}^{N} \Delta T(r, t)$

$\sigma_{\Delta T}(r)=\sqrt{\frac{1}{N} \sum_{t \in \tau}^{N}\left(\Delta T(r, t)-\mu_{\Delta T}(r)\right)^{2}}$.

In this paper, a $7 \mathrm{yr}$ data set of the bi-angular AATSR gridded brightness temperature with a coverage of longitude from 5 to $25^{\circ} \mathrm{E}$ and latitude from 35 to $50^{\circ} \mathrm{N}$ and the duration from 2003 to 2009 during the months of March and April has been processed for computing $\mu_{\Delta T}(r)$ and $\sigma_{\Delta T}(r)$ reference fields shown in Figs. 3 and 4.

\subsection{Anomalous detection step}

Anomalous TIR of bi-angular AATSR data are detected by an index as used in Tramutoli (1998, 2007), implementing RETIRA (Robust Estimator of TIR Anomalies), which can be defined as follows:

$\otimes_{\Delta T}(r, t)=\frac{\Delta T(r, t)-\mu_{\Delta T}(r)}{\sigma_{\Delta T}(r)}$.

The difference $\Delta T(r, t)-\mu_{\Delta T}(r)$ then represents the Signal $(S)$ to be investigated for its possible relation with seismic activities. It is always evaluated by comparison with the corresponding natural/observational noise $(N)$, represented by $\sigma_{\Delta T}(r)$ which describes the overall (local) variability of $\mathrm{S}$ including all (natural and observational, known and unknown) sources of its variability, as historically observed at the same 

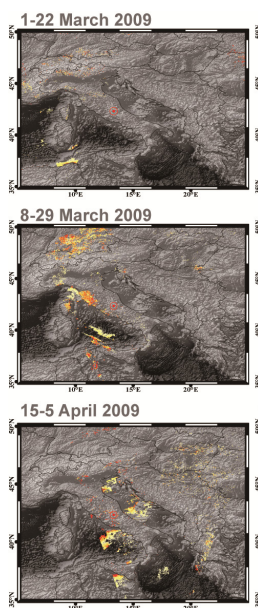

22-12 A pril 2009

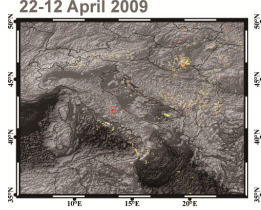

29-19 A pril 2009

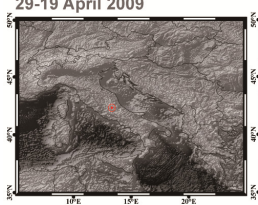

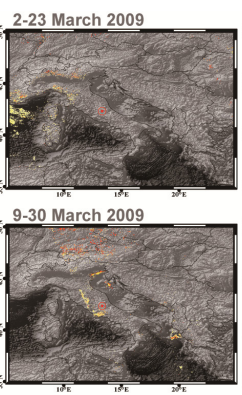

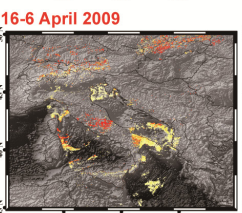

23-13 April 2009

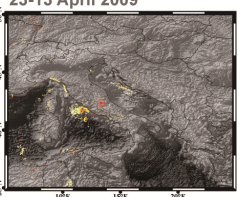

30-20 April 2009

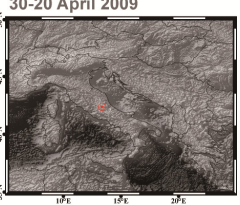

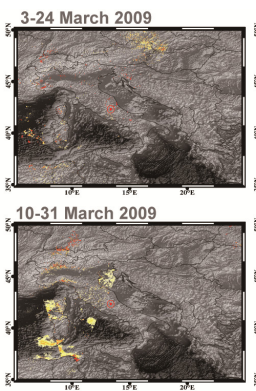

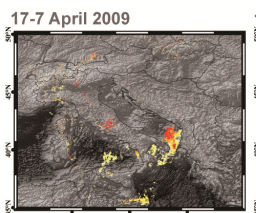

24-14 April 2009

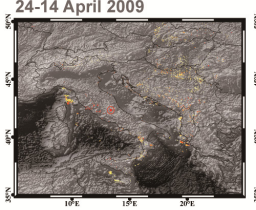

31-21 April 2009

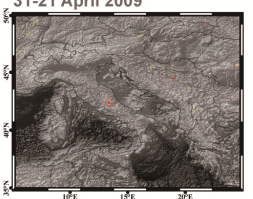

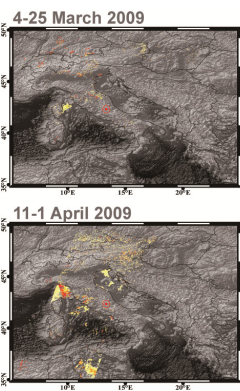

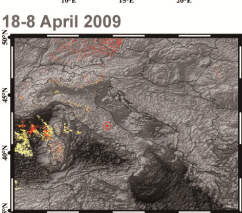

25-15 April 2009
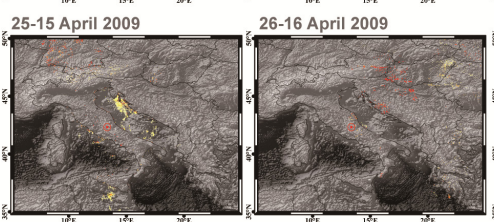

19-9 A pril 2009
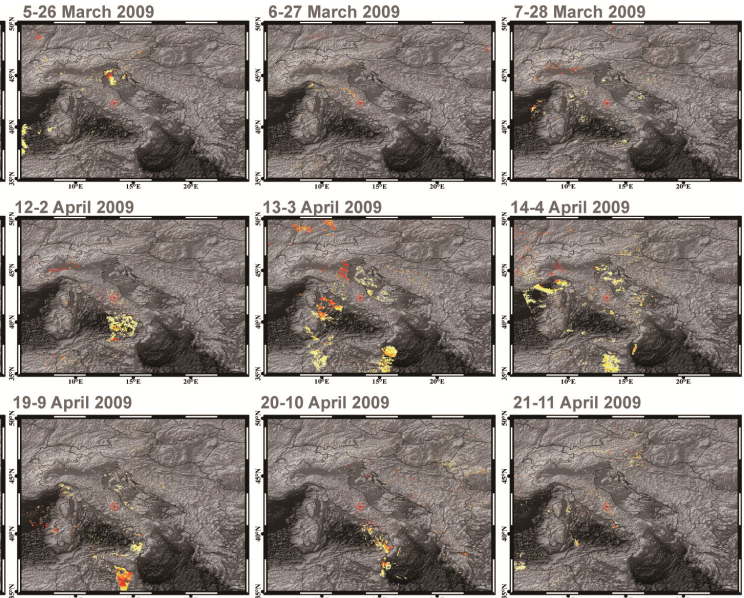

20-10 April 2009

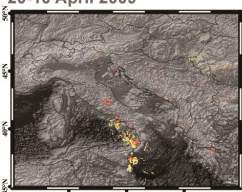

21-11 April 2009

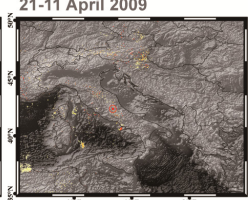

27-17 April 2009

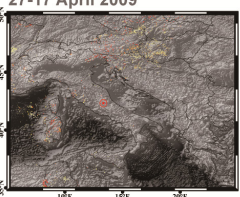

28-18 April 2009

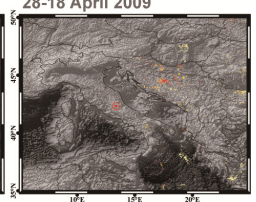

Fig. 5. Results of the RETIRA index computation on the investigated area before and after the Abruzzo earthquake using AATSR BT data (nadir view) from 22 March 2009 to 21 April 2009. Pixels with $\otimes_{\Delta T}(r, t)>4$ are depicted in mars red, pixels with $3.5<\otimes_{\Delta T}(r, t)<4$ are depicted in seville orange, pixels with $3.0<\otimes_{\Delta T}(r, t)<3.5$ are depicted in solar yellow, pixels with $2.5<\otimes_{\Delta T}(r, t)<3.0$ are depicted in autunite yellow, pixels with $2.0<\otimes_{\Delta T}(r, t)<2.5$ are depicted in yucca yellow. Epicentre is marked with a red bullseye.

site in similar observational conditions (sensor, time of day, month, etc.). This way, the relative importance of the measured TIR signal (or the intensity of anomalous TIR transients) can naturally be evaluated in terms of a $S / N$ ratio by the RETIRA index. Moreover the larger $\sigma_{\Delta T}(r)$ is, the lower $\otimes_{\Delta T}(r, t)$ will be, so that the RETIRA index results intrinsically protect against false alarm proliferation (robustness) (Tramutoli et al., 2005).

In this paper, the RETIRA index has been computed for a set of bi-angular AATSR imagery data in order to perform the validation/confutation analyses. For validation purposes, the months of March and April 2009 have been considered, whereas, for the confutation analysis, the months of March and April 2008 were selected, as 2008 was seismically "unperturbed" (i.e. no earthquakes with $M \geq 5$, data acquired in the same region and month but different years) in the whole data set used (USGS, 2009).

\section{Validation analysis}

Using the method mentioned above and the bi-angular AATSR top-of-atmosphere (TOA) brightness temperature
(BT) data from 22 March to 21 April 2009, we get the curves (Fig. 5) of results of the RETIRA index computation on the investigated area before and after the Abruzzo earthquake using AATSR nadir view data and the curves (Fig. 6) of results of the RETIRA index computation using AATSR forward view data. Pixels with $\otimes_{\Delta T}(r, t)>4$ are depicted in mars red, pixels with $3.5<\otimes_{\Delta T}(r, t)<4$ are depicted in seville orange, pixels with $3.0<\otimes_{\Delta T}(r, t)<3.5$ are depicted in solar yellow, pixels with $2.5<\otimes_{\Delta T}(r, t)<3.0$ are depicted in autunite yellow, pixels with $2.0<\otimes_{\Delta T}(r, t)<2.5$ are depicted in yucca yellow. The epicentre is marked with a red bullseye, the investigated area has longitude from $5^{\circ} \mathrm{E}$ to $25^{\circ} \mathrm{E}$ and latitude from 35 to $50^{\circ} \mathrm{N}$.

In Fig. 5, it can be observed that there are obvious anomalies before the earthquake except for the day before the earthquake. The anomalies occurred during 29 March to 5 April 2009, which is the period beginning eight days before the Abruzzo earthquake. All of the anomalies are around the Abruzzo earthquake epicentre. These anomalies may be caused by the large amount of energy generated by the Abruzzo earthquake, while anomalies on the day when the earthquake occurred (Fig. 5) become more apparent, which may be caused by the release of a large amount of energy; 


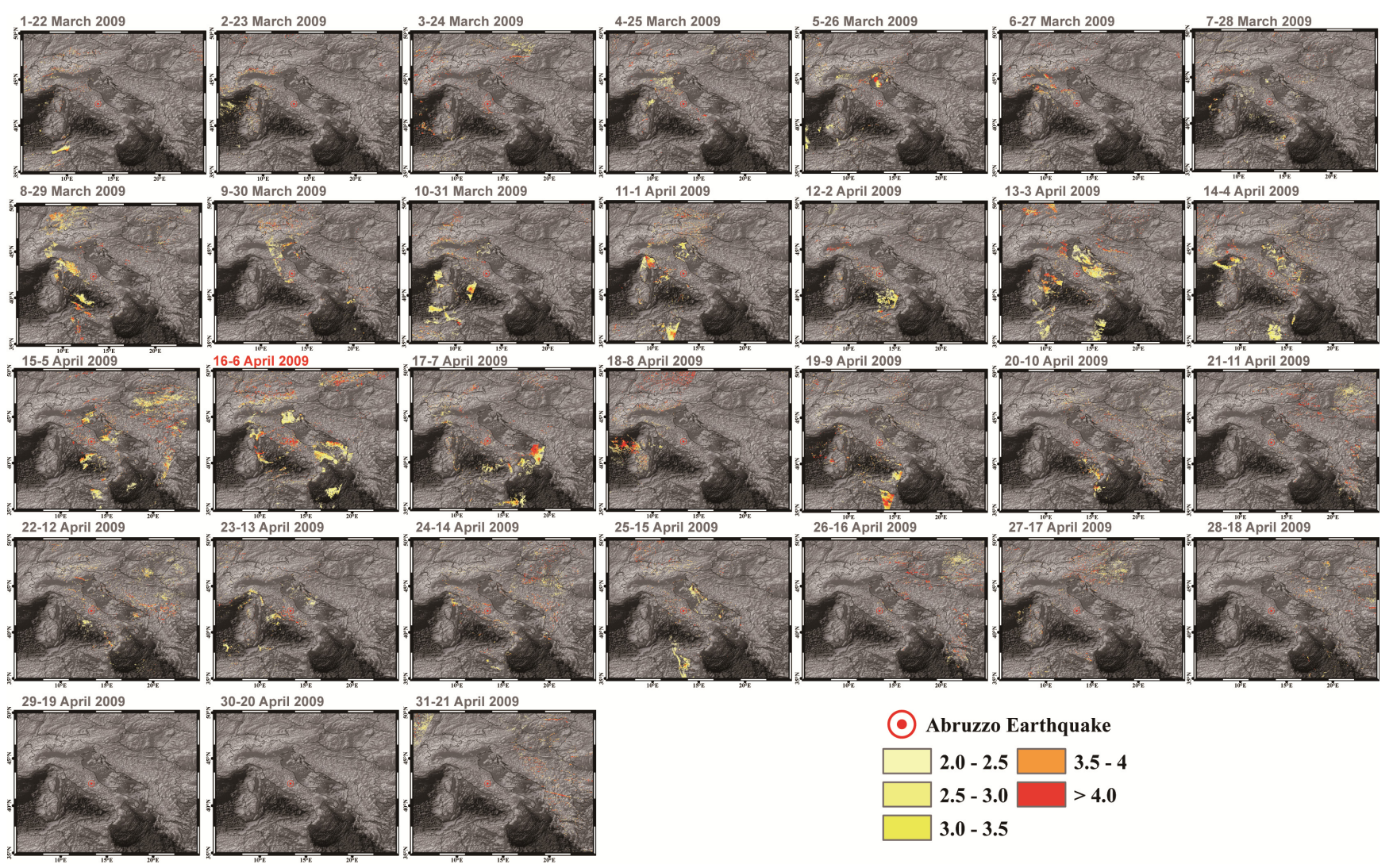

Fig. 6. Results of the RETIRA index computation on the investigated area before and after the Abruzzo earthquake using AATSR BT data (forward view) from 22 March 2009 to 21 April 2009.

after the earthquake, in the results of the RETIRA index computation of 7 April 2009, 8 April 2009, 9 April 2009, 10 April 2009, 13 April 2009 and 15 April 2009, some anomalies are also present, which perhaps is due to the many aftershocks of the Abruzzo earthquake (Fig. 1).

Beginning 29 March 2009 anomalies are visible in central Italy. They are located near the main tectonic lineaments and the area where the epicentres of the Abruzzo earthquake cluster. This indicates that from 28 March 2009 to 5 April 2009, anomalies were identified as likely indicative of activity in this area, in correspondence with a tectonic explanation of spatial and temporal continuity. TIR anomalies also occurred in the Balkan area, with a variable spatial distribution and different levels of intensity; a possible reason for this is that, before the Abruzzo earthquake, the region was affected by the earthquake $\left(M_{\mathrm{w}}=4.6\right)$ that occurred on 5 April 2009, which resulted in a small amount of energy release.

The distribution of the anomalies in Fig. 6 is similar to that in Fig. 5. However, in Fig. 6, the anomalies are more continuous with larger magnitudes and a clear anomaly appears during the earthquake. The bi-directional observation AATSR data could be the main reason to cause such effect. The AATSR field of view comprises two $\sim 500 \mathrm{~km}$-wide curved swaths, with 555 pixels across the nadir swath and 371 pixels across the forward swath. The nominal IFOV (instantaneous field of view; pixel) size is $1 \mathrm{~km}^{2}$ at the centre of the nadir swath and $1.5 \mathrm{~km}^{2}$ at the centre of the forward swath, and the conical scanning mechanism of the AATSR gives a dual view of the Earth's surface, in the forward view at an angle of around $55^{\circ}$ and in the nadir view at an angle close to vertical (from 0 to $21.7^{\circ}$ ). These phenomena are quite clear in the results of the RETIRA index computation of 31 March, 1 April, 3 April, 5 April, and 11 April 2009. The anomalies extracted based on AATSR forward view data acquired with an angle of around $55^{\circ}$ are large (Fig. 6). The anomalies acquired from the AATSR nadir view data are small (Fig. 5). According to the above analysis, the character of the anomalies could be summarized as follows.

1. Anomalies from 29 March 2009 to 5 April 2009 could be obviously observed, the largest magnitude anomalies appear on 6 April 2009 and gradually weaken after 15 April 2009, thus we postulated that such effect would result from the large energy flux during the Abruzzo earthquake.

2. A feature of the anomalies caused by the earthquake is a variable persistence in the space and time domains, 

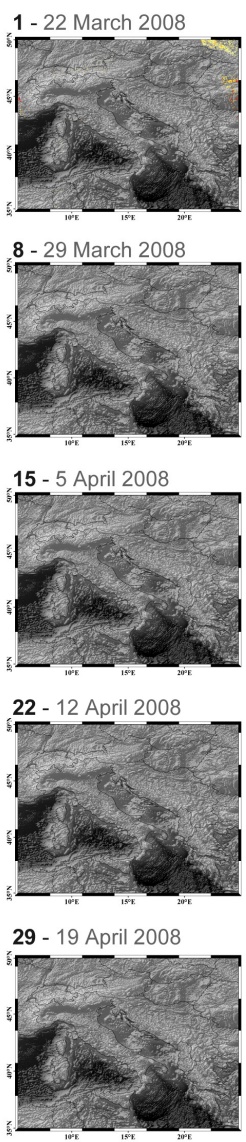
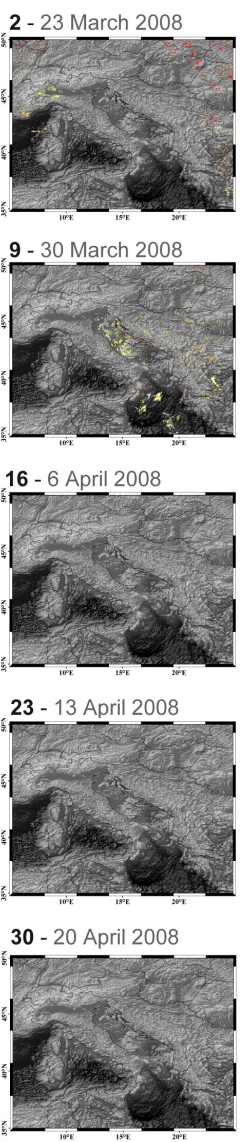
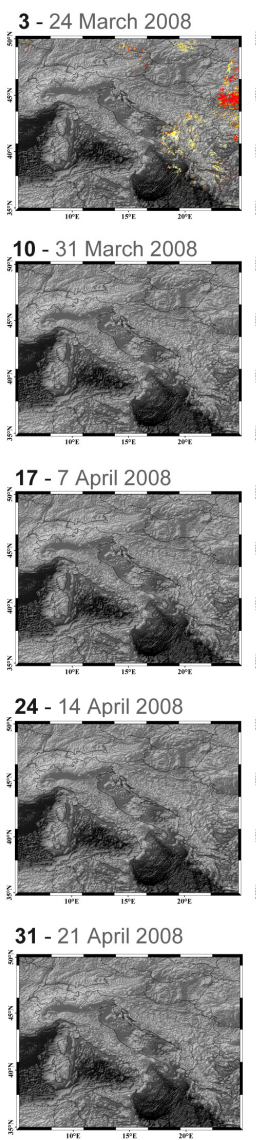
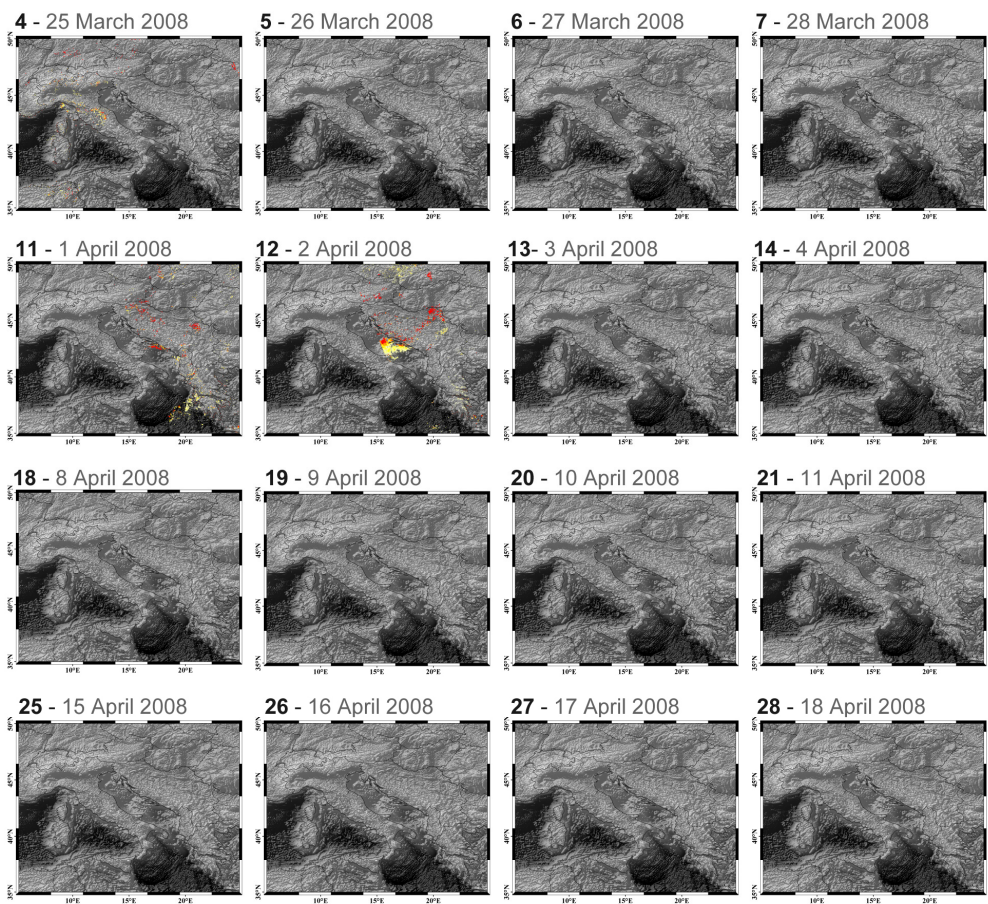

Fig. 7. Results of the RETIRA index computation on the investigated area from 22 March 2008 to 21 April 2008 using AATSR BT data (nadir view).

with a variable spatial distribution and different levels of intensity.

3. From the above discussion, using the bi-directional observations AATSR data could help us to have a further understanding of seismic TIR anomalies.

\section{Confutation analysis}

In order to examine the reliability of the analysed results (above) regarding the Abruzzo earthquake, we use the same procedure to perform a confutation analysis on a relatively seismically unperturbed period: the same period (from 22 March to 21 April) but in a different year (2008) in the same area. The reason for selecting 2008 for the confutation analysis is that within the years 2000 and 2009 there were no seismic events with a magnitude greater than 5 in the investigated area as illustrated in Fig. 2, according to the seismic catalogue (USGS, 2009).

The anomalies in Fig. 7 are generally limited in extent and discontinuous. Only isolated anomalous pixels are detected. Anomalies from 22 March 2008 to 24 March 2008 are present, the largest magnitude anomalies appear on 24 March 2008 and disappear after that. Considering the historic seismicity (from March 2008 to April 2008) of the Abruzzo region (Fig. 2), we postulated that such effect could result from the energy flux of the earthquake that occurred on 24 March $2008\left(M_{\mathrm{s}}=4.1\right)$. Other sporadic anomalies (31 March 2008, 1 April 2008 and 2 April 2008) could have been affected by the seismic event with magnitude 4.2 that occurred on 31 March 2008.

\section{Conclusion}

This paper presents a validation and confutation analysis of the AATSR gridded brightness temperature data associated with the Abruzzo earthquake and explains how the anomalies discovered from the AATSR gridded brightness temperature data could be related to the earthquake. The methodology discussed in the paper uses RST, including spatial/temporal continuity analysis of the RETIRA index to identify singularities during the earthquakes. The validation and confutation analyses on time and space of the Abruzzo earthquakes conclude that prominent singularities could be found prior to the 
earthquakes using RETIRA index, which showed continuity both in space and time.

The conclusion regarding anomalies discussed in this paper could be summarized as follows: several anomalies that may be caused by the large amount of energy generated are identified before the Abruzzo earthquake. Anomalies on the day when the earthquake occurred could also be detected, which may have been caused by the release of a large amount of energy. After the earthquake obvious anomalies were also observed, which perhaps were caused by the many aftershocks. From the confutation analysis, we conclude that the anomalies observed from 29 March 2009 to 5 April 2009, about eight days before Abruzzo earthquake, could be the earthquake anomalies associated with the Abruzzo earthquake.

The distinguishing feature of this paper is that we carried out a validation and confutation analysis of seismic anomalies from bi-directional observations, which could help us to have a further understanding of seismic TIR anomalies. Our studies also found that anomalies discovered within biangular AATSR data could be regarded as effective indicators to detect seismic activities. This finding will be further validated by using more earthquake data in the future.

Acknowledgements. This work is founded by Civil Specific Advance Research Program on Science-Technology, and Industry for National Defense (Grant No.: 60128303 and Grant No.: Y1K0030044), International Science \& Technology Cooperation Program of China (Project No. 2010DFA21880), Integrated geo-spatial information technology and its application to resource and environmental management towards the GEOSS (Proposal No. 247608) and National Natural Science Foundation of China (NSFC, Grant No.: 41271451). The authors would like to acknowledge the European Space Agency (ESA) for making AATSR data available for various research communities, and thank David K. Keefer and anonymous referees for their constructive comments.

Edited by: D. Keefer

Reviewed by: two anonymous referees

\section{References}

Aliano, C., Corrado, R., Filizzola, C., Pergola, N., and Tramutoli, V.: Robust Satellite Techniques (RST) for Seismically Active Areas Monitoring: the Case of 21st May, 2003 Boumerdes/Thenia (Algeria) Earthquake, Analysis of Multi-temporal Remote Sensing Images, 2007, MultiTemp 2007, International Workshop on Analysis of Multi-temporal Remote Sensing Images, 1-6, 2007.

Aliano, C., Corrado, R., Filizzola, C., Pergola, N., and Tramutoli, V.: Robust satellite techniques (RST) for the thermal monitoring of earthquake prone areas: the case of Umbria-Marche October, 1997 seismic events, Ann. Geophys., 51, 451-459, doi:10.4401/ag-3025, 2008.

Campbell, J. W. and Hooker, S. B.: SeaWiFS Technical Report Series: Level-3 SeaWiFS Data Products: Spatial and Temporal Bin- ning Algorithms, National Aeronautics and Space Administration, Goddard Space Flight Center, 1995.

Cervone, G., Kafatos, M., Napoletani, D., and Singh, R. P.: Wavelet maxima curves of surface latent heat flux associated with two recent Greek earthquakes, Nat. Hazards Earth Syst. Sci., 4, 359374, doi:10.5194/nhess-4-359-2004, 2004.

Coll, C., Valor, E., Galve, J. M., Mira, M., Bisquert, M., GarcíaSantos, V., Caselles, E., and Caselles, V.: Long-term accuracy assessment of land surface temperatures derived from the Advanced Along-Track Scanning Radiometer, Remote Sens. Environ., 116, 211-225, doi:10.1016/j.rse.2010.01.027, 2012.

Corrado, R., Caputo, R., Filizzola, C., Pergola, N., Pietrapertosa, C., and Tramutoli, V.: Seismically active area monitoring by robust TIR satellite techniques: a sensitivity analysis on low magnitude earthquakes in Greece and Turkey, Nat. Hazards Earth Syst. Sci., 5, 101-108, doi:10.5194/nhess-5-101-2005, 2005.

Defu, L., Zhuoli, L., and Keyin, P.: OLR anomalous phenomena before strong earthquakes, Earthquake, 17, 126-132, 1997.

Dey, S. and Singh, R. P.: Surface latent heat flux as an earthquake precursor, Nat. Hazards Earth Syst. Sci., 3, 749-755, doi:10.5194/nhess-3-749-2003, 2003.

ESA: Envisat AATSR Product Handbook, European Space Agency, 2007.

Filizzola, C., Pergola, N., Pietrapertosa, C., and Tramutoli, V.: Robust satellite techniques for seismically active areas monitoring: a sensitivity analysis on September 7, 1999 Athens's earthquake, Phys. Chem. Earth, Parts A/B/C, 29, 517-527, doi:10.1016/j.pce.2003.11.019, 2004.

Genzano, N., Aliano, C., Filizzola, C., Pergola, N., and Tramutoli, V.: A robust satellite technique for monitoring seismically active areas: the case of Bhuj-Gujarat earthquake, Tectonophysics, 431, 197-210, 2007.

Genzano, N., Aliano, C., Corrado, R., Filizzola, C., Lisi, M., Mazzeo, G., Paciello, R., Pergola, N., and Tramutoli, V.: RST analysis of MSG-SEVIRI TIR radiances at the time of the Abruzzo 6 April 2009 earthquake, Nat. Hazards Earth Syst. Sci., 9, 2073-2084, doi:10.5194/nhess-9-2073-2009, 2009.

Genzano, N., Corrado, R., Coviello, I., Grimaldi, C. S. L., Filizzola, C., Lacava, T., Lisi, M., Marchese, F., Mazzeo, G., Paciello, R., Pergola, N., and Tramutoli, V.: A multi-sensors analysis of RSTbased thermal anomalies in the case of the Abruzzo earthquake, Geoscience and Remote Sensing Symposium (IGARSS), 2010 IEEE International, 761-764, 2010.

Gorny, V., Salman, A., and Tronin, A.: The earth outgoing IR radiation as an indicator of seismic activity, Proc. Acad. Sci. USSR, 30, 67-69, 1988.

Hayakawa, O. A. M., Kodama, T., and Tanaka, T.: On a possibility to monitor seismic activity using satellites, Adv. Space Res., 26, 993-996, 2000.

Liperovsky, V. A., Meister, C.-V., Liperovskaya, E. V., Davidov, V. F., and Bogdanov, V. V.: On the possible influence of radon and aerosol injection on the atmosphere and ionosphere before earthquakes, Nat. Hazards Earth Syst. Sci., 5, 783-789, doi:10.5194/nhess-5-783-2005, 2005.

Liperovsky, V. A., Meister, C.-V., Liperovskaya, E. V., and Bogdanov, V. V.: On the generation of electric field and infrared radiation in aerosol clouds due to radon emanation in the atmosphere before earthquakes, Nat. Hazards Earth Syst. Sci., 8, 1199-1205, doi:10.5194/nhess-8-1199-2008, 2008. 
Liperovsky, V. A., Meister, C.-V., Mikhailin, V. V., Bogdanov, V. V., Umarkhodgaev, P. M., and Liperovskaya, E. V.: Electric field and infrared radiation in the troposphere before earthquakes, Nat. Hazards Earth Syst. Sci., 11, 3125-3133, doi:10.5194/nhess-113125-2011, 2011.

Liu, J. Y., Chuo, Y. J., Shan, S. J., Tsai, Y. B., Chen, Y. I., Pulinets, S. A., and Yu, S. B.: Pre-earthquake ionospheric anomalies registered by continuous GPS TEC measurements, Ann. Geophys., 22, 1585-1593, doi:10.5194/angeo-22-1585-2004, 2004.

Llewellyn-Jones, D., Edwards, M., Mutlow, C., Birks, A., Barton, I., and Tait, H.: AATSR: global-change and surface-temperature measurements from Envisat, ESA bulletin, 105, 11-21, 2001.

Ouzounov, D. and Freund, F.: Mid-infrared emission prior to strong earthquakes analyzed by remote sensing data, Adv. Space Res., 33, 268-273, 2004.

Ouzounov, D., Liu, D., Chunli, K., Cervone, G., Kafatos, M., and Taylor, P.: Outgoing long wave radiation variability from IR satellite data prior to major earthquakes, Tectonophysics, 431, 211-220, 2007.

Parrot, M., Berthelier, J., Lebreton, J., Sauvaud, J., Santolik, O., and Blecki, J.: Examples of unusual ionospheric observations made by the DEMETER satellite over seismic regions, Phys. Chem. Earth, Parts A/B/C, 31, 486-495, 2006.

Pergola, N., Aliano, C., Coviello, I., Filizzola, C., Genzano, N., Lacava, T., Lisi, M., Mazzeo, G., and Tramutoli, V.: Using RST approach and EOS-MODIS radiances for monitoring seismically active regions: a study on the 6 April 2009 Abruzzo earthquake, Nat. Hazards Earth Syst. Sci., 10, 239-249, doi:10.5194/nhess10-239-2010, 2010.

Pulinets, S. and Boyarchuk, K.: Ionospheric precursors of earthquakes, Springer Verlag, 2004.

Pulinets, S. and Ouzounov, D.: Lithosphere-AtmosphereIonosphere Coupling (LAIC) model - An unified concept for earthquake precursors validation, J. Asian Earth Sci., 41, 371-382, doi:10.1016/j.jseaes.2010.03.005, 2011.

Pulinets, S., Ouzounov, D., Karelin, A., Boyarchuk, K., and Pokhmelnykh, L.: The physical nature of thermal anomalies observed before strong earthquakes, Phys. Chem. Earth Parts A/B/C, 31, 143-153, 2006.

Qin, K., Wu, L., De Santis, A., and Wang, H.: Surface latent heat flux anomalies before the Ms 7.1 New Zealand earthquake 2010, Chinese Science Bulletin, 56, 3273-3280, doi:10.1007/s11434011-4680-z, 2011.

Sarkar, S., Gwal, A., and Parrot, M.: Ionospheric variations observed by the DEMETER satellite in the mid-latitude region during strong earthquakes, J. Atmos. Sol.-Terr. Phys., 69, 15241540, 2007.

Tramutoli, V.: Robust AVHRR Techniques (RAT) for Environmental Monitoring theory and applications, Earth Surf. Remote Sens. II, 3496, 101-113, 1998.
Tramutoli, V.: Robust Satellite Techniques (RST) for Natural and Environmental Hazards Monitoring and Mitigation: Theory and Applications, International Workshop on Analysis of Multitemporal Remote Sensing Images, 1-6, 2007.

Tramutoli, V., Di Bello, G., Pergola, N., and Piscitelli, S.: Robust satellite techniques for remote sensing of seismically active areas, Ann. Geophys., 44, 295-312, doi:10.4401/ag-3596, 2001.

Tramutoli, V., Cuomo, V., Filizzola, C., Pergola, N., and Pietrapertosa, C.: Assessing the potential of thermal infrared satellite surveys for monitoring seismically active areas: The case of Kocaeli (İzmit) earthquake, August 17, 1999, Remote Sens. Environ., 96, 409-426, doi:10.1016/j.rse.2005.04.006, 2005.

Tronin, A. A.: Satellite thermal survey - a new tool for the study of seismoactive regions, Int. J. Remote Sens., 17, 1439-1455, doi:10.1080/01431169608948716, 1996.

Tronin, A. A., Hayakawa, M., and Molchanov, O. A.: Thermal IR satellite data application for earthquake research in Japan and China, J. Geodynam., 33, 519-534, 2002.

Tronin, A. A., Biagi, P. F., Molchanov, O. A., Khatkevich, Y. M., and Gordeev, E. I.: Temperature variations related to earthquakes from simultaneous observation at the ground stations and by satellites in Kamchatka area, Phys. Chem. Earth, 29, 501-506, doi:10.1016/j.pce.2003.09.024, 2004.

Umarkhodgaev, R. M., Liperovsky, V. A., Mikhailin, V. V., Bogdanov, V. V., Meister, C.-V., and Liperovskaya, E. V.: IR spectral analysis for the diagnostics of crust earthquake precursors, Nat. Hazards Earth Syst. Sci., 12, 3269-3274, doi:10.5194/nhess-123269-2012, 2012.

USGS: The United States Geological Survey, availablat at: http://earthquake.usgs.gov/earthquakes/eqinthenews/2009/ us2009fcaf/\#summary (last access: 8 March 2013), 2009.

Xiong, P., Bi, Y., and Shen, X.: Study of Outgoing Longwave Radiation Anomalies Associated with Two Earthquakes in China Using Wavelet Maxima, in: Hybrid Artificial Intelligence Systems, edited by: Corchado, E., Wu, X., Oja, E., Herrero, Á., and Baruque, B., Lecture Notes in Computer Science, Springer Berlin Heidelberg, 77-87, 2009.

Xiong, P., Shen, X. H., Bi, Y. X., Kang, C. L., Chen, L. Z., Jing, F., and Chen, Y.: Study of outgoing longwave radiation anomalies associated with Haiti earthquake, Nat. Hazards Earth Syst. Sci., 10, 2169-2178, doi:10.5194/nhess-10-2169-2010, 2010.

Závody, A. M., Mutlow, C. T., and Llewellyn-Jones, D. T.: Cloud clearing over the ocean in the processing of data from the AlongTrack Scanning Radiometer (ATSR), J. Atmos. Ocean. Technol., 17, 595-615, 2000. 